\title{
A carreira transimperial de don Manuel Cipriano de Melo no rio da Prata do século XVIII*
}

\author{
Fabrício Prado \\ The College of William and Mary \\ Williamsburg, Virginia, EUA \\ fpprado@wm.edu
}

RESUMO

O presente artigo examina a trajetória e as redes sociais de um súdito português e espanhol, don Manuel Cipriano de Melo, que cruzou fronteiras e mudou sua lealdade política diversas vezes para explorar as relaçôes entre redes transimperiais, comunidades regionais e dinâmicas imperiais no período colonial. A trajetória de Cipriano de Melo exemplifica como grupos regionais utilizaram redes transimperiais para incrementar seu status e poder dentro da conjuntura imperial, assim como oferece uma oportunidade para a análise do papel de dinâmicas transimperiais em áreas não privilegiadas dentro do sistema comercial espanhol. Para reconstruir a trajetória de vida de Cipriano de Melo esta pesquisa contou com fontes documentais depositadas em arquivos na Argentina, Uruguai, Brasil, Portugal, Espanha e Estados Unidos.

Palavras-chave: redes sociais; contrabando; mundo atlântico; rio da Prata colonial, comércio.

\section{ABSTRACT}

The present article examines the life story and social networks of a Portuguese-Spanish subject, don Manuel Cipriano de Melo, who crossed borders and switched allegiances multiple times in his life, to illuminate the interaction between trans-imperial networks, local groups and imperial dynamics in the late colonial period. Melo's life story shows how local groups manipulated trans-imperial networks to improve their status within the empire; moreover, it provides a unique opportunity for examining the role of trans-imperial dynamics in commercial peripheral areas of empire. In order to reconstruct Cipriano de Melo's trajectory, I cross-referenced sources deposited in archives in Argentina, Uruguay, Brazil, Portugal, Spain and the United States.

Keywords: social networks; contraband; commerce; Atlantic world; colonial Rio de la Plata.

\footnotetext{
* Gostaria de agradecer ao Programa de Pós-Graduação em História da Emory University pelo financiamento dessa pesquisa. Agradeço também aos pareceristas anônimos, bem como à profa. dra. Lise Sedrez pelos comentários e sugestóes editoriais que em muito enriqueceram o presente trabalho. Agradeço finalmente ao prof. dr. Arturo Ariel Bentancur pelas sugestóes e o estímulo para o desenvolvimento da presente pesquisa. Tradução do inglês de Meggie Rosar Fornazari. Artigo recebido em 20 de janeiro de 2012 e aceito em 10 de setembro de 2012.
} 
No século XVIII, poderosas redes sociais, políticas e econômicas cruzaram fronteiras políticas que uniram sociedades em ambos os lados do oceano Atlântico. Essas redes serviram como avenidas pelas quais indivíduos circularam, estabelecendo ligaçóes em diversas regióes a fim de mobilizar recursos, tanto de forma local quanto remota. Nascido em Lisboa por volta de 1742, don Manuel Cipriano de Melo cresceu em Buenos Aires e mais tarde conduziu negócios na costa da África, em Salvador, Colônia do Sacramento, Rio de Janeiro e Londres antes de se firmar em Montevidéu. Por toda a sua vida, Cipriano de Melo mudou de lealdades imperiais e mudou-se diversas vezes; apesar disto, suas redes comerciais, familiais e religiosas foram mantidas em estabilidade. Sua carreira dinâmica e intrincada não o impediu de tornar-se alto oficial na burocracia espanhola de Montevidéu, assim como tornar-se um dos membros mais notáveis dessa comunidade.

A vida de Cipriano de Melo representa as redes transimperiais fluidas características do mundo atlântico do século XVIII e oferece uma oportunidade de analisar a relação entre um indivíduo e tais redes. As redes transimperiais serviram como pontes nas quais indivíduos mobilizavam recursos econômicos, políticos e sociais. Além disso, o controle de tais redes permitia que grupos locais desenvolvessem um senso de comunidade dentro dos impérios espanhol e português. As redes transimperiais forneciam oportunidades econômicas, políticas e sociais para as comunidades periféricas, servindo como alternativa além daquelas oferecidas pelos centros de poder locais.

Ao observar o modo com o qual indivíduos manipulavam ou se envolviam com redes transimperiais, ligaçôes importantes entre os impérios no mundo atlântico vêm à tona, com maior foco nas ligaçôes entre agentes históricos em vez de processos econômicos e políticos formais. O estudo sobre esse assunto foi revitalizado nas últimas décadas por uma série de trabalhos que enfatizaram a inter-relação de processos econômicos e sociais que se desenrolaram nos três continentes da bacia do Atlântico. ${ }^{1}$ Apesar disso, tais trabalhos pioneiros têm escopo limitado: primeiro, pela geografia (o Atlântico Norte), e, segundo, pelas fronteiras políticas dos impérios como o Atlântico britânico e espanhol. Consequentemente, tais estudos enfatizam processos que se desenrolaram entre unidades políticas que se assemelham a fronteiras nacionais contemporâneas. Desse modo, o estudo da interaçáo entre impérios posicionou o Estado no centro da análise, favorecendo a pesquisa sobre aspectos militares ou diplomáticos da interação transimperial.

No início da década de 1990, historiadores do império português questionaram a significância e a eficácia de políticas mercantilistas que garantiam o papel privilegiado da metrópole em termos políticos e econômicos, enfatizando especificamente o papel das elites locais na construção do império e na governança do espaço colonial. ${ }^{2}$ Analisar diversas fontes em conjunto (como registros públicos, registros religiosos e correspondência pessoal, assim como uma referência cruzada de evidências de diversos acervos) trouxe a dinâmica imperial à tona e reforçou o argumento pela importância da periferia nos desenvolvimentos de centros de poder imperial. Como resultado, uma série de trabalhos acadêmicos enfatizou a importância de redes baseadas no comércio, família, amizade e religião entre os impérios atlânticos. ${ }^{3}$ Apesar disso, tais análises ficaram limitadas nas mesmas fronteiras políticas e geográficas dos impérios do Atlântico.

\footnotetext{
${ }^{1}$ Para maior discussão sobre a perspectiva Atlântica, ver a Introdução em MANCKE, Elizabeth; SHAMMAS, Carole (Ed.). The creation of the British Atlantic world. Baltimore: Johns Hopkins University Press, 2005. p. 2-5. Sobre a interconectividade dos processos imperiais, ver LISS, Peggy K. Atlantic empires: the network of trade and revolution, 17131826. Baltimore: Johns Hopkins University Press, 1983; e ADELMAN, Jeremy. Revolution and sovereignty in the Iberian Atlantic. Princeton: Princeton University Press, 2006.

${ }^{2}$ FRAGOSO, João; GOUVEA, Maria F.; BICALHO, Fernanda. O antigo regime nos trópicos. Rio de Janeiro: Civilização Brasileira, 2000.

${ }^{3}$ BOTTCHER, Nikolaus; HAUSBERGER, Bernd; IBARRA, Antonio (Coord.). Redes y negocios globales en el mundo ibérico. Cidade do México: El Colegio de Mexico, 2011.
} 
Em outras áreas do Atlântico, interaçóes humanas ultrapassaram as fronteiras designadas pelas metrópoles políticas. ${ }^{4}$ A regiáo do rio da Prata, como local de interação transimperial, é um dos maiores exemplos de tal dinâmica. No século XVIII, essa região surgiu como palco de disputas coloniais entre Portugal e Espanha e como local de interesse para a Grã-Bretanha e a França.

$\mathrm{Na}$ região do rio da Prata, particularmente em Montevidéu, o controle de redes transimperiais, em conjunto com a manipulação de políticas reformistas imperiais, criou comunidades distintas que vieram à tona dentro do domínio do império espanhol. Mais especificamente, a clara diferença entre uma comunidade com interesses centrados em Montevidéu e a comunidade centrada em Buenos Aires. Tal processo de formação identitária colonial na região se situa dentro de um contexto que é anterior à criação das naçóes modernas. ${ }^{5}$

Como homem de negócios português que serviu a ambos os impérios ibéricos em momentos distintos de sua vida, Cipriano de Melo estendeu suas redes além dos limites imperiais a fim de melhor manipular recursos e melhorar sua posição dentro do império para o qual ele servia no momento. A história de vida de Cipriano de Melo é utilizada a fim de examinar o impacto destas ligaçóes — as redes verticais e horizontais com as quais ele tinha ligaçóes dentro e fora das fronteiras imperiais. A experiência de Cipriano de Melo foi um exemplo típico da experiência de muitos de seus contemporâneos; entretanto, devido ao seu papel central em diversas destas redes, ele pôde também concentrar vantagens advindas de tais redes. Mais do que apenas a biografia de um indivíduo, suas açóes servem de pano de fundo para analisar a significância de redes na periferia do fim do período colonial. ${ }^{6}$

O século XVIII foi marcado por uma série de tratados entre os impérios atlânticos que se refletiram em mudanças significativas no equilíbrio de poder na Europa e em espaços coloniais. Portugal e Espanha, especialmente após a Guerra da Sucessão Espanhola (1705-1713), tornaram-se econômica e politicamente dependentes da Inglaterra e da França, respectivamente. Ao passo que os poderes ibéricos perceberam sua posiçáo como potências secundárias entre os impérios atlânticos, a rivalidade entre eles cresceu enquanto as duas partes tentavam melhorar a posição de um em relação ao outro. ${ }^{7}$ Após a Guerra dos Sete Anos (1756-1763), uma onda reformista varreu o Atlântico, o que levou a uma reorganização completa dos impérios coloniais. As monarquias ibéricas elaboraram novas políticas militares, administrativas, econômicas e sociais em suas colônias americanas. Tais políticas são conhecidas na historiografia como as reformas Bourbônicas e Pombalinas. ${ }^{8}$ De acordo com o historiador Dauril Alden,

\footnotetext{
${ }^{4}$ Para a importância das redes transatlânticas nas dinâmicas imperiais, ver o pioneiro estudo de BOXER, Charles. Salvador de Sá e a luta pelo Brasil e Angola. São Paulo: Nacional; Edusp, 1973.

${ }^{5}$ Para uma discussão sobre a questão de identidade regional em contextos coloniais, CANNY, Nicholas P.; PAGDEN, Anthony (Ed.). Colonial identity in the Atlantic world, 1500-1800. Princeton: Princeton University Press, 1987; e FRAGOSO, João. A nobreza da República: notas sobre a formação da primeira elite senhorial do Rio de Janeiro (séculos XVI e XVII). Topoi: Revista de História, Rio de Janeiro, v. 1, p. 45-122, jan./dez. 2000.

${ }^{6}$ Para a importância, significado, e dinâmica sobre redes sociais: LEVI, Giovanni. A herança imaterial: trajetória de um exorcista no Piemonte do século XVII. Rio de Janeiro: Civilização Brasileira, 2000; MOUTOUKIAS, Zacarias. Las formas complejas de la acción política: justicia corporativa, faccionalismo y redes sociales (Buenos Aires 1750-1760). Jarbuch fur Geschichte Lateinamerikas, v. 39, p. 69-102, 2002; IMÍZCOZ, José María (Ed.). Casa, familia y sociedad: País Vasco, España y América, siglos XV-XIX. Bilbao: Servicio Editorial, Universidad del País Vasco, 2004; BERTRAND, Michel. De la familia a la red de sociabilidade. Revista Mexicana de Sociología, v. 61, n. 2, p. 107-135, 1999.

${ }^{7}$ Acerca da progressiva importância das potências mediadoras para os impérios ibéricos, ou seja, França e Inglaterra: STEIN, Stanley; STEIN, Barbara. Silver, trade and war: Spain and America in the making of early modern Europe. Baltimore: Johns Hopkins University Press, 2000. p. 120-141; e FISHER, Harold Edward Stephen. The Portugal trade: a study of Anglo Portuguese commerce, 1700-1770. Londres: Methuen, 1971. p. 30-42.

${ }^{8}$ Para reformas nos impérios espanhol e britânico no século XVIII, ver ELLIOT, John. Atlantic empires of the $18^{\text {th }}$ century. Cambridge: Oxford University Press. 2006. Para o império português: CURTO, Diogo; BETHENCOURT, Francisco (Ed.). The Portuguese oceanic expansion 1400-1800. Cambridge: Cambridge University Press, 2007.
} 
as décadas de 1760 e 1770 marcaram o clímax da rivalidade luso-espanhola nas Américas. A região do rio da Prata foi crucial na disputa entre os dois impérios ibéricos. ${ }^{9}$

A regiáo do rio da Prata foi alvo de interesse e disputa entre Portugal e Espanha desde o século XVII. Apesar de periférica no sistema mercantil espanhol, a região atraiu constantemente mercadores estrangeiros interessados em seu mercado interior: peles e, em especial, a prata que fluía de Potosí para dentro da economia local. A fundação da cidade portuguesa de Colônia do Sacramento em 1680, em frente a Buenos Aires, foi a estratégia de Portugal para garantir expansão territorial e a navegação no estuário de La Plata, assim como a criação de uma central comercial a fim de utilizar a prata do império espanhol. A Colônia do Sacramento foi, por quase um século, um grande entreposto de contrabando que fornecia açúcar, tecidos, rum, escravos e outros produtos atlânticos para a região, tornando-se o epítome da criação e manutenção para redes sociais e comerciais estáveis que ligavam as Américas portuguesa e espanhola. ${ }^{10}$ Apesar disso, a presença portuguesa na bacia do rio da Prata nunca foi aceita pela Coroa espanhola. Em diversas ocasióes, as forças espanholas conquistaram Sacramento (em 1680, 1705, 1762 e 1777), mas Portugal conseguiu recuperar a cidade diplomaticamente com forte apoio britânico, com exceção de 1777.11 A Coroa espanhola também respondeu ao expansionismo português na margem norte do rio da Prata com a fundação de Montevidéu em 1726, controlando então o melhor porto natural do estuário. ${ }^{12}$ Apesar de tornar-se a sede de uma governança militar na década de 1750, Montevidéu enfrentou crescimento demográfico e econômico lento até as últimas décadas do século XVIII.

Reformas iniciadas na metade da década de 1770 mudaram radicalmente a geografia do poder na região do rio da Prata. Destas reformas, as mais importantes foram a criação do Vice-Reinado do Rio da Prata, com capital em Buenos Aires, a expulsão dos portugueses da Colônia do Sacramento e o estabelecimento de Montevidéu como porto principal espanhol na regiáo. Após a conquista da Colônia do Sacramento pelas forças espanholas em 1777, muitos portugueses se mudaram para Montevidéu e para o interior da Banda Oriental. Utilizando-se de redes anteriormente estabelecidas, os habitantes recém-chegados entraram em contato com grupos mercantis centralizados em Montevidéu, a fim de renovar ligaçôes de contrabando com mercadores portugueses e britânicos. Além disso, devido ao seu excelente porto, as reformas de Bourbon estabeleceram Montevidéu como porto obrigatório e o único autorizado para desembarque de escravos no rio da Prata. Por fim, Montevidéu tornou-se a base naval da frota sul-americana e a sede das autoridades encarregadas de combater o contrabando, na terra e no mar. ${ }^{13}$ O primeiro oficial nomeado pelo vice-rei Cevallos para a repressáo do contrabando em Montevidéu foi don Manuel Cipriano de Melo.

\footnotetext{
${ }^{9}$ ALDEN, Dauril. Royal government in colonial Brazil. Berkeley: University of California Press, 1968. Especial atenção é dada às políticas luso-brasileiras no rio da Prata em "Debatable lands".

${ }^{10}$ PRADO, Fabrício. A Colônia do Sacramento: o extremo sul da América portuguesa no século XVIII. Porto Alegre: F. P. Prado, 2002. p. 191-193.

${ }^{11}$ A despeito das repetidas demandas portuguesas por apoio militar inglês no rio da Prata em 1777, o Império Britânico evitou confrontos com a Espanha em virtude da guerra de independência das Treze Colônias anglo-americanas da América do Norte.

${ }^{12}$ A fundação de Montevidéu pelos espanhóis em 1726 foi uma reação à tentativa luso-brasileira de fortificar a baía de mesmo nome em 1824. A fundação espanhola de Montevidéu foi realizada pelo governador de Buenos Aires, Bruno Mauricio de Zavala; os soldados luso-brasileiros expulsos da área tomaram refúgio na Colônia do Sacramento.

${ }_{13}$ Para maiores detalhes sobre o impacto das reformas de Bourbon na burocracia imperial no rio da Prata: SOCOLOW, Susan. The bureaucrats of Buenos Aires, 1769-1810. Durham: Duke University Press, 1989; LYNCH, John. Spanish colonial administration, 1782-1810: the intendant system in the Viceroyalty of the Río de la Plata. Nova York: Greenwood Press, 1969.
} 


\section{Antecedentes luso-brasileiros}

Nascido em uma família abastada de Lisboa em 1740, don Manuel Cipriano de Melo ficou órfão antes de completar 10 anos de idade. Devido a conhecidos da família, ele foi mandado para o Brasil, sob os cuidados do governador do Rio de Janeiro, Gomes Freire de Andrade. Em 1749, o governador mandou o jovem Cipriano para o rio da Prata, passando seus cuidados para o governador da Colônia do Sacramento, don Garcia de Bivar. Apesar disso, pouco após chegar ao rio da Prata, Cipriano de Melo fugiu da Colônia do Sacramento para Buenos Aires, onde por fim ele foi apadrinhado pelo governador espanhol Joseph de Andonaegui. ${ }^{14}$

Entre 1754 e 1756, os guaranis tapes das Sete Missões Orientais do Rio Uruguay se rebelaram contra as cláusulas do Tratado de Madri (1750) que estipulavam a troca da Colônia do Sacramento pelo território das sete missóes jesuíticas na Banda Oriental. Em 1754, Cipriano de Melo foi voluntário das forças espanholas durante a chamada Guerra Guaranítica (1754-1756). Em certa ocasião, inclusive, Cipriano de Melo viajou até o campo de batalha em uma canoa. Como protegido do governador de Buenos Aires, Cipriano de Melo provavelmente teve a oportunidade de interagir com outras autoridades regionais, como o governador da Colônia do Sacramento e, principalmente, com o governador de Montevidéu, José Joaquin de Viana. Na adolescência, o conflito deu a Cipriano de Melo a oportunidade de se familiarizar com a região e com as autoridades, com as quais ele compartilhou experiências de guerra.

Uma vez que a campanha conjunta dos ibéricos contra os guaranis revoltosos terminou, Cipriano de Melo foi a Cádiz, onde estudou ciências náuticas e foi apresentado à cultura teatral da cidade. Após a conclusão de seus estudos, Cipriano de Melo retornou a Lisboa a fim de receber sua herança. Em seguida, ele voltou ao rio da Prata, desembarcando na Colônia do Sacramento com bagagem pesada e quatro escravos. ${ }^{15}$

Na Colônia do Sacramento, Cipriano de Melo se estabeleceu como capitão de navios no estuário do rio da Prata. ${ }^{16}$ Durante a campanha militar de 1762 contra a Colônia do Sacramento, liderada pelo novo governador de Buenos Aires (don Pedro de Cevallos), Cipriano de Melo trocou de lado e foi nomeado piloto da frota espanhola para o ataque à Colônia do Sacramento. Ele lutou contra portugueses e britânicos durante o bloqueio naval da Colônia do Sacramento, tomando 260 prisioneiros. De qualquer modo, Cipriano de Melo voltou a trabalhar sob bandeiras portuguesas em 1763, quando a Colônia do Sacramento foi devolvida para Portugal como parte de um acordo diplomático. ${ }^{17}$

Nas décadas seguintes, Cipriano de Melo cruzou o oceano Atlântico, fazendo negócios na Colônia do Sacramento, em Salvador da Bahia, Lisboa, Londres, no Rio de Janeiro e no oeste africano. Cipriano de Melo se viu novamente no rio da Prata em 1765. Ele se casou com Ana Joaquina da Silva, filha de um grande mercador local, na Colônia do Sacramento. O dote recebido foi de 30 mil pesos. ${ }^{18}$ Além disso, Cipriano de Melo estabeleceu uma posição duradoura como comerciante e piloto devido a sua proximidade às autoridades, como o governador e negociantes de destaque da colônia portuguesa. ${ }^{19}$ Por causa disso, ele cruzou fronteiras imperiais comercializando diversos bens como açúcar, tabaco, tecidos, madeiras, mobília, papel e escravos.

\footnotetext{
${ }^{14}$ CUTOLO, Vicente Osvaldo. Nuevo diccionario biográfico argentino. Buenos Aires: Editorial Elche, 1975. p. 520.

${ }^{15}$ BENTANCUR, Arturo Ariel. Don Cipriano de Melo, señor de fronteras. Montevidéu: Arca, 1985. p. 9-12; CUTOLO,

Vicente Osvaldo. Nuevo diccionario biográfico argentino. Buenos Aires: Editorial Elche, 1975. p. 520-521.

${ }_{16}$ Termo de Assentada, Colônia do Sacramento, 19 fev. 1776. Biblioteca Nacional de Lisboa (BNL), Manuscritos Pombalinos, cod. 10855 .

${ }^{17}$ CUTOLO, Vicente Osvaldo. Nuevo diccionario biográfico argentino, op. cit. p. 520-521.

${ }^{18}$ Ibidem.

${ }_{19}$ Termo de Assentada, Colônia do Sacramento, 19 fev. 1776. BNL, Manuscritos Pombalinos, cod. 10855.
} 
Alguns dos mercadores mais abastados da Colônia do Sacramento e do Rio de Janeiro se encontravam entre seus parceiros de negócios, além de autoridades governamentais. Cipriano de Melo fez negócios extensivos com o coronel João de Azevedo Souza, poderoso mercador residente da Colônia do Sacramento que emprestava dinheiro ao governo local com frequência e era do mesmo círculo social de don Brás Carneiro Leão, um mercador poderoso no Rio de Janeiro. ${ }^{20}$ Outros parceiros de negócios na Colônia do Sacramento incluíam os mercadores don Mamede João e don Joseph da Costa Ferreira, e o famoso contrabandista João da Cunha Neves. Além disso, Cipriano de Melo foi nomeado pelo governador como um dos homens de maior distinçáo da Colônia do Sacramento a depor no Conselho Ultramarino sobre o estado da colônia. ${ }^{21}$ Cipriano de Melo obteve acesso às redes do Rio de Janeiro por meio de parceiros de negócios da Colônia do Sacramento, o que o ligou diretamente a alguns dos mercadores mais abastados de lá que faziam negócios extensivos com o tráfico de escravos no Atlântico Sul. ${ }^{22}$

Em 1777, uma frota espanhola transportando mais de 10 mil soldados, liderados pelo recém-nomeado vice-rei espanhol don Pedro Antonio de Cevallos, aportou no rio da Prata. Cevallos tinha ordens para estabelecer um vice-reinado em Buenos Aires e para expulsar os portugueses da Colônia do Sacramento. Mais uma vez, Cevallos encarregou Cipriano de Melo de pilotar em um esquadrão para conquistar a Colônia do Sacramento. Em junho daquele ano, a Colônia do Sacramento caiu sob o jugo espanhol, sendo completamente destruída. Consequentemente, Cipriano de Melo e centenas de cidadãos portugueses juraram lealdade ao rei da Espanha. Mais tarde, Cipriano de Melo mudou-se para Montevidéu, e como recompensa pelos serviços prestados à Coroa espanhola foi nomeado para a Comandancia del Resguardo, uma nova secretaria encarregada de reprimir o contrabando. ${ }^{23}$

Após a mudança para Montevidéu, Cipriano de Melo encontrou-se em uma posição estratégica, não somente por sua posição na burocracia espanhola, mas também por suas ligaçôes. Como segundo comandante del Resguardo, Cipriano de Melo foi encarregado de controlar portos e regular a navegação em lagos e lagoas, contando com 32 homens sob suas ordens. É importante notar que ele foi responsável tanto por determinar a legalidade de desembarques no porto, quanto pela inspeção dessas cargas. Além disso, Melo recebeu compensação da Coroa espanhola pelas propriedades possuídas por ele na Colônia do Sacramento, além de uma licença para importar o equivalente a 32 mil pesos de mercadoria do Brasil: escravos, tabaco, açúcar, cachaça e outros bens. ${ }^{24}$ Todos estes fatores garantiram sua entrada privilegiada na sociedade de Montevidéu.

Restabelecido ali, Cipriano de Melo tinha todos os meios, recursos e conhecimento necessários para reconectar as rotas comerciais entre o Rio de Janeiro e o rio da Prata, cujo centro até então tinha sido a Colônia do Sacramento. Cipriano de Melo garantiu não somente a legalidade e a segurança das operações, mas também acumulou capital suficiente para financiar seus próprios negócios. Se o conhecimento sobre os mercados e produtos luso-brasileiros era importante, a entrada na comunidade local também

\footnotetext{
${ }^{20}$ Lista das Letras que se passaram sobre a Thezouraria Geral do Erario da Cap. do Rio de Janeiro (em diante Lista das Letras). Colônia do Sacramento, 8 jun. 1776. BNL, Manuscritos Pombalinos, cod. 10855, 1776.

${ }^{21}$ Cartas do governador Francisco José da Rocha. Colônia do Sacramento, 8 fev. 1776. BNL, Manuscritos Pombalinos, cod. 10855 .

${ }^{22}$ Francisco Antonio Maciel a Francisco Jose de Luzena. Montevideo, 12 nov. 1783. Archivo General de Indias, Sevilla (AGI), Buenos Aires Gobierno, Leg. 333. Ver também FRAGOSO, João. Homens de grossa ventura: acumulação e hierarquia na praça mercantil do Rio de Janeiro, 1790-1830. Rio de Janeiro: Civilização Brasileira, 1993. p. 319-332.

${ }^{23}$ Representacion de Don Manuel Cipriano de Melo para que se declare se debe ser considerado extranjero o sudito de SMC y goce de los fueros apropriados (ou Representacion de Don Manuel Cipriano de Melo). AGI, Buenos Aires Gobierno. Leg 311, 1783.

${ }^{24}$ Representacion de Don Manuel Cipriano de Melo. AGI, Buenos Aires Gobierno. Leg 311, 1783. Expediente del Virrey Marques de Loreto con el Intendente de Buenos Aires Francisco Paula Sanz sobre el Arreglo de los Campos de Montevideo. AGI, Buenos Aires Gobierno, Leg. 333, 1786.
} 
era crucial; um grupo de mercadores importantes recebeu Cipriano de Melo de braços abertos em seu meio, ávido para lucrar com o novo estado de Montevidéu com o império espanhol. Tais acordos locais foram fundamentais para o crescimento do mercantilismo local e da comunidade política.

\section{Montevidéu e as conexões luso-brasileiras}

Em 1780, Francisco Maciel, mercador de Montevidéu e grande parceiro de negócios de Cipriano de Melo, partiu em viagem de negócios para o Rio de Janeiro. De acordo com o vice-rei luso-brasileiro, don Luis de Vasconcelos, Maciel agiu como delegado representando os interesses dos mercadores de Montevidéu. Ele se reuniu com mercadores e autoridades no Rio de Janeiro a fim de adquirir 90 escravos e comprar tabaco, açúcar, e tecidos. Apesar disto, a parte mais importante de sua viagem foi restabelecer a rota de comércio entre o Rio de Janeiro e o rio da Prata. Maciel garantiu que navios portugueses seriam bem-vindos a Montevidéu, especialmente alegando necessidade de aportar para reparos, sendo esta uma garantia apresentada pelo segundo comandante Cipriano de Melo. ${ }^{25}$ Apesar da estratégia suspeita, o vice-rei recebeu garantia de don Brás Carneiro Leão, mercador de "boa reputação e grande crédito" no Rio de Janeiro, dando testemunho da confiabilidade das autoridades e dos mercadores de Montevidéu e garantindo a segurança dos navios. ${ }^{26}$

Entre os anos de 1781 e 1786, 74 navios portugueses aportaram em Montevidéu, 43 destes declarando seu destino para outros portos portugueses no Rio Grande do Sul ou em Santa Catarina no momento da partida. Entre os capitáes que faziam essa rota frequentemente estavam pilotos portugueses encarregados de navios portugueses e espanhóis. Além disso, alguns dos capitães portugueses eram parceiros de negócios e de amigos de Cipriano de Melo que faziam a rota entre Montevidéu e o Rio de Janeiro carregando açúcar, tabaco e escravos. Em Montevidéu, eles eram hospedados na casa de Cipriano de Melo ou eram convidados para seus jantares. ${ }^{27}$

Cipriano de Melo também atuou como mercador na rota rio da Prata-América lusa. Em 1779, ele peticionou a Coroa espanhola pela permissáo para cobrar dinheiro que mercadores luso-brasileiros lhe deviam. O débito dos mercadores da América portuguesa totalizava aproximadamente 32 mil pesos. A fim de dar fundamentação ao seu pedido, Cipriano de Melo coletou depoimentos de diversos homens de negócios situados na Colônia do Sacramento, em Buenos Aires e Montevidéu que confirmavam o fato de Cipriano de Melo ter crédito nas cidades do Rio de Janeiro e Salvador da Bahia, bem como na ilha de Santa Catarina. Além disso, Cipriano de Melo também tinha diversos depoimentos de um oficial espanhol que lutou a seu lado em 1777, atestando os bons serviços prestados por Cipriano de Melo à Coroa espanhola. A Coroa deferiu a petição de Cipriano de Melo, autorizando o vice-rei Cevallos

\footnotetext{
${ }^{25}$ Francisco Antonio Maciel a Luis de Vasconcelos. Rio de Janeiro, 30 mar. 1780. Arquivo Histórico Ultramarino, Lisboa (AHU), Rio de Janeiro, Doc. 9294. Para uma análise abrangente e detalhada do comércio de contrabando no Rio de Janeiro no final do século XVIII, e a importância das rotas para o rio da Prata, ver: PIJNIG, Ernst. Controlling contraband: mentality, economy and society in $18^{\text {th }}$ century Rio de Janeiro. Tese (doutorado) — Programa de Pós-Graduação em História, Johns Hopkins University, 1997. p. 148-182.

${ }^{26}$ Luís de Vasconcelos e Sousa ao Martinho de Melo e Castro. Rio de Janeiro 12 jul. 1781. AHU, Rio de Janeiro, doc. 9561; e Representacion de Don Manuel Cipriano de Melo. AGI, Buenos Aires Gobierno. Leg 311, 1783. Brás Carneiro Leão declarou para autoridades espanholas que possuía dívidas com Cipriano de Melo oriundas de transaçôes comerciais anteriores, da época da Colônia do Sacramento.

${ }^{27}$ Autos Seguidos entre Dn. Manuel Perez y Dn. Miguel Josef de Fleitas sobre anular la venta de unos esclavos que el segundo hizo al primero, 1794. Archivo General de la Nación, Uruguay (AGN, Uruguay), Escribanía de Gobierno y Hacienda (EGH), caja 22, exp. 38. Os pilotos eram Miguel de Fleitas, Antonio João da Cunha e Leonardo Perdigão. Miguel de Fleitas e Cipriano de Melo romperam uma parceria comercial no decorrer deste processo.
} 
a compensá-lo não apenas por sua propriedade perdida na Colônia do Sacramento, mas também pela propriedade de seu sogro don Manuel Pereira Gonzáles, que fugira para o Rio de Janeiro em $1777 .{ }^{28}$

Cipriano de Melo encontrou aliados importantes entre os mercadores e autoridades de Montevidéu (ver figura 1). O grupo responsável pela maior parte da integraçáo de Cipriano de Melo na sociedade de Montevidéu foi a família Viana e seus aliados, que também tencionavam lucrar com o novo estado da cidade como porto atlântico e de seus negócios no porto de Buenos Aires. O clã incluía o antigo governador de Montevidéu, José Joaquín de Viana; seu primo, Melchor de Viana; o mercador Don Francisco Maciel e, mais tarde, o próprio Cipriano de Melo. As redes familiais dos Viana os ligaram aos primeiros colonos da Banda Oriental, garantindo favores da Coroa para suas famílias devido a seus esforços na construção da cidade. ${ }^{29}$

O primeiro governador de Montevidéu, don José Joaquín de Viana, desposou doña Francisca de Alzaybar, irmã de don Francisco de Alzaybar — o primeiro latifundiário da Banda Oriental. Em dois mandatos separados, Viana governou Montevidéu por 15 anos: de 1751 a 1764 e de 1771 a 1773 . Durante esse período, o governador pôde criar fortes redes na cidade. A ligação com a família Alzaybar não somente garantia acesso a amplos recursos econômicos e sociais na região, mas também garantia mercedes (favores) da Coroa e da família Alzaybar, que dava assistência aos habitantes espanhóis e patrulhava o rio da Prata. ${ }^{30}$ Além disso, Viana liderou as tropas espanholas durante a Guerra Guaranítica, o que lhe deu direito a favores reais. Nas décadas seguintes, Joaquín de Viana foi responsável pela distribuição de terras, escolhendo os dois governadores de Montevidéu que o sucederam (Agustín de La Rosa e Joaquín Del Pino, respectivamente), garantindo no processo um papel de importância na região para si e para sua família. ${ }^{31}$

Don Joaquín de Viana construiu uma rede extensa de parentes biológicos e religiosos, além de parceiros de negócios importantes nas últimas décadas do século XVIII em Montevidéu. Por exemplo, Joaquín de Viana era primo de don Melchor de Viana, que comercializava escravos e todo tipo de bens da Europa e das Américas, o que fez dele um dos mercadores mais importantes de Montevidéu. Além disso, Joaquín de Viana nomeou a irmã de outro poderoso mercador, don Francisco Maciel, como sua inventariante. Maciel foi também um dos mercadores de escravos mais ativos de Montevidéu.

Apesar disso, as ligações de Viana se estendiam além da comunidade mercadora de Montevidéu. O governador era protegido político do vice-rei Juan José Vértiz, que atuou como governador de Buenos Aires entre 1770 e 1776, e como vice-rei de 1778 a 1784. Entre os mercadores de Buenos Aires, Martín de Altolaguirre tinha a reputação de ser um bom parceiro de negócios, além de aliado político. ${ }^{32}$ Outro personagem importante deste grupo foi don Francisco de Medina, o comerciante abastado responsável pela criação do primeiro saladero da Banda Oriental. ${ }^{33}$

Após a queda da Colônia do Sacramento, esta rede de elites locais recebeu Cipriano de Melo em Montevidéu de braços abertos, incorporando-o como parceiro de negócios e também como amigo. Cipriano de Melo, Melchor de Viana e Francisco Maciel contratavam os mesmos navios e pilotos, e é

\footnotetext{
${ }^{28}$ Autos Formados por la Prision del Portugues Juan de Acuña. AGI Gobierno, Buenos Aires, Leg. 333, 1785. Francisco de Paula Sanz. Buenos Aires 06, oct. 1784. AGI Gobierno, Buenos Aires, Leg. 333.

${ }_{29}$ APOLANT, J. Alejandro. Génesis de la familia uruguaya: los habitantes de Montevideo en sus primeros 40 ańos, filiaciones, ascendencias, entronques, descendencias. Montevidéu: s.n., 1975. p. 931-940.

${ }^{30}$ Para maiores detalhes sobre a família Alzaybar e sua influência sobre Montevidéu, ver PRADO, Fabrício. In the shadows of empires: trans-imperial networks and colonial identity in Bourbon río de la Plata. Diss. (Ph.D.) — Emory University, 2009. Chapter 3.

${ }^{31}$ APOLANT, J. Alejandro. Génesis de la familia uruguaya, op. cit. p. 931-933.

${ }^{32}$ Ibidem, p. 935-937, 967.

${ }^{33}$ BENTANCUR, Arturo Ariel. Don Cipriano de Melo, señor de fronteras, op. cit. p. 20-25. No inventário de Medina, Cipriano de Melo aparece como credor de mais de 2 mil pesos.
} 
importante ressaltar que também compartilhavam as mesmas redes no Rio de Janeiro e em Salvador da Bahia. ${ }^{34}$ Esses mercadores utilizaram os mesmos agentes e fizeram pedidos de bens conjuntamente, com base nos contatos de Cipriano de Melo, para adquirirem produtos gerais e específicos, como cadeiras feitas de jacarandá e cozinheiros escravos da Bahia. ${ }^{35}$ Tais operaçóes dependiam diretamente de plena confiança. Devido à natureza do comércio transimperial, o nível de informalidade era muito maior do que nas tradicionais redes de comércio intraimperiais. $\mathrm{O}$ último era muito mais baseado em regulamentos legais do que em relaçóes interpessoais.

As ligaçôes transimperiais de Cipriano de Melo beneficiaram grupos situados em Montevidéu e mercadores de Buenos Aires que tinham comércio ativo com vendedores traficantes de escravos de colônias estrangeiras. Montevidéu tornou-se o porto preferido da região, não somente por causa das reformas bourbônicas, mas também devido a suas redes luso-platinas; $O$ porto de Montevidéu preenchia o vazio deixado pela Colônia do Sacramento como centro das redes de comerciantes portugueses e espanhóis na região. Como resultado, Montevidéu tornou-se o porto de maior importância tanto para o comércio legalizado quanto para o ilegal.

Durante períodos de guerra entre a Espanha e a Grã-Bretanha, regulamentos menos severos sobre o comércio com naçóes amigas permitiram que as redes transimperiais funcionassem ainda mais ativamente e com maior nível de legalidade. $\mathrm{O}$ tráfego intenso no porto de Montevidéu nos anos seguintes à queda da Colônia do Sacramento foi de início bem-vindo pelos comerciantes de Buenos Aires. Entretanto, o crescente poder da comunidade mercadora de Montevidéu e os oficiais que detinham o controle do comércio transimperial começaram a incomodar facçóes importantes em Buenos Aires.

\section{O crescimento de Montevidéu como um porto atlântico no rio da Prata}

Em meados da década de 1780, alguns dos mercadores e autoridades em Buenos Aires estavam insatisfeitos com o fato de Montevidéu ser o único porto autorizado para entrada de transatlânticos no Prata. Como resultado dessa disposiçáo, os mercadores de Buenos Aires dependiam de seus procuradores e parceiros de negócios em Montevidéu, o que criava meios para que a comunidade mercadora de Montevidéu aumentasse seu fluxo de negócios. Apesar disso, nem todo mercador de Buenos Aires era contrário ao novo papel desempenhado pela cidade de Montevidéu. Um grupo emergente de mercadores sem contratos de monopólio, que atuavam em empreitadas como o tráfico de escravos, comércio com colônias estrangeiras e no comércio livre com outros portos do império espanhol, não reclamava do novo papel da cidade de Montevidéu. Alguns dos membros de maior visibilidade neste grupo incluíam don Juan de Aguirre, Tomás Antonio Romero e seu filho don José de Maria. ${ }^{36}$

A nomeação de um novo vice-rei em Buenos Aires iniciou o conflito entre algumas facçôes das comunidades mercantis nas duas cidades portuárias. Segmentos importantes da comunidade mercantil de Buenos Aires receberam em Buenos Aires o vice-rei de braços abertos, o marquês de Loreto Cristóbal Del Campo, no ano de 1784. Determinado a encerrar o intenso tráfego transimperial que era canalizado por Montevidéu, o vice-rei implementou medidas desenvolvidas para restringir os "excessos" de autonomia e as atividades de contrabando das autoridades em Montevidéu. ${ }^{37}$

\footnotetext{
${ }^{34}$ Autos Formados por la Prision del Portugues Juan de Acuña. AGI Gobierno, Buenos Aires, Leg. 333, 1785.

${ }^{35}$ Ibidem.

${ }^{36}$ Para maiores informaçôes acerca dos mercadores de Buenos Aires e as transformações da comunidade mercantil na segunda metade do século XVII, ver SOCOLOW, Susan. Los mercaderes de Buenos Aires vireinal: familia y comercio. Trans. Alicia Steimberg. Buenos Aires: Editorial de la Flor, 1991; GRIECO, Viviana L. Politics and public credit: the limits of absolutism in late colonial Buenos Aires. Diss. (Ph.D.) - Emory University, 2005.

${ }^{37}$ Autos Formados por la Prision del Portugues Juan de Acuña. AGI Gobierno, Buenos Aires, Leg. 333, 1785.
} 
Além da questão do contrabando, o conflito envolveu uma disputa entre o vice-rei Del Campo e o intendente do rio da Prata, don Francisco de Paula Sanz. No rio da Prata, o vice-rei e o intendente frequentemente viam suas jurisdiçôes em sobreposição, ou com definiçôes vagas. ${ }^{38}$ Além disso, a chegada do marquês de Loreto gerou opiniôes divergentes sobre as políticas de comércio com navios de naçóes amigas, e sobre como estimular a indústria local da melhor maneira possível. De um lado, o intendente Sanz buscava proteger o comércio, além de estaleiros e fábricas locais; por outro lado, o vice-rei Del Campo tinha o objetivo de proteger as políticas que privilegiavam o comércio com a Espanha. O conflito podia ser visto como pontos de vista diferentes sobre a política imperial, ou como um conflito entre a antiga e a nova estrutura de poder criada pelas reformas bourbônicas. Entretanto, ressentimentos pessoais entre os dois homens, juntamente com suas lealdades às diversas facçóes às quais eles serviam, também devem ser levados em consideração.

Um dos alvos de maior visibilidade da reação porteña foi Cipriano de Melo. O vice-rei e outras autoridades o acusaram de apoiar o contrabando ao permitir que navios portugueses aportassem em Montevidéu e, portanto, facilitando a introdução ilegal de bens e de escravos em domínios espanhóis. ${ }^{39}$ Os eventos que culminaram em uma série de processos contra Cipriano de Melo começaram quando um de seus parceiros de negócios, o conhecido piloto e contrabandista português don Antonio Joseph de Acuña, foi preso após entrar ilegalmente em Montevidéu, onde ficou hospedado por dois dias na casa de Cipriano de Melo. Acuña havia entrado na cidade a bordo de um bergantim português que havia aportado em Montevidéu dois dias antes. De acordo com seu depoimento, ele foi até a casa de Cipriano de Melo devido a suas ligaçóes com don Melchor de Viana. Acuña justificou sua presença na cidade ao alegar que precisava cobrar uma dívida desse mercador.

O episódio culminou em um longo processo, no qual autoridades de Buenos Aires acusavam a Cipriano de Melo e questionavam a habilidade das autoridades de Montevidéu para controlar o comércio transatlântico. A disputa centrou-se em quem tinha jurisdição para inspecionar os navios e autorizar o desembarque de bens. O caso complicou-se por dois motivos: primeiro, pois as infraçóes de Acuña estavam sob a jurisdiçáo dos oficiais da alfândega, que na época estavam sob influência direta do novo vice-rei e das autoridades portenhas; e, segundo, pois dentre os pertences de Acuña que haviam sido confiscados foram encontrados cartas, recibos e livros de contabilidade de operaçóes que envolviam Cipriano de Melo, sua esposa Ana Joaquina, Melchor de Viana, Francisco Maciel e outros mercadores importantes de Montevidéu.

Durante o processo, as autoridades expuseram uma rede intrincada de cooperação entre mercadores de Montevidéu. De acordo com provas citadas no caso, Cipriano de Melo e sua esposa operavam um negócio duradouro que enviava escravos importados ilegalmente para o Alto Peru. Alegava-se que o casal exportava entre 27 e 300 escravos em cada operação, utilizando um de seus próprios escravos para gerenciar as entregas. ${ }^{40} \mathrm{O}$ vice-rei também questionou a legitimidade da licença de Cipriano de Melo para trazer 32 mil pesos fuertes da América lusa. De acordo com o vice-rei Del Campo, Cipriano de Melo afirmara que havia transportado menos de 5 mil pesos até aquele momento. Entretanto, o vice-rei argumentou que Cipriano de Melo tinha cinco navios sob seu comando no Brasil; portanto, o vice-rei calculou que a quantidade carregada em cada navio seria cerca de mil pesos, o que não era suficiente para cobrir as custas da viagem do navio e de sua tripulaçáo.

As provas expuseram redes clandestinas de contrabando ainda maiores, que envolviam o piloto português Juan de Acuña e os mercadores de Montevidéu Leonardo Pereyra, Melchor de Viana, Francisco

\footnotetext{
38 Sobre a burocracia no rio da Prata, ver SOCOLOW, Susan M. The bureaucrats of Buenos Aires, 1769-1810. Durham: Duke University Press, 1987.

${ }^{39}$ Autos Formados por la Prision del Portugues Juan de Acuña. AGI Gobierno, Buenos Aires, Leg. 333, 1785.

${ }^{40}$ Ibidem.
} 
Maciel e Francisco de Medina. Os documentos de Acuña revelaram que, por mais de quatro anos, esses mercadores haviam contrabandeado escravos, açúcar, tabaco e outros bens, e haviam também exportado peles ilegalmente para o Rio de Janeiro e para Salvador da Bahia. Essas operaçóes somavam mais de 51.400 pesos fuertes. ${ }^{41}$ No Rio de Janeiro, Cipriano de Melo contava com a parceria de don Antonio João da Costa, João da Costa Pinheiro, João Diniz Vieira e don Brás Carneiro Leão. O representante do grupo em Salvador da Bahia era don Francisco José de Lucena. O fato de os grupos terem mais ligaçóes no Rio de Janeiro do que em Salvador da Bahia é algo revelador. Além do alto número de parceiros de negócios no porto fluminense, don Franciso Maciel reclamou de um antigo parceiro na Bahia, Manoel José Froes, que náo havia pagado pelas 5.697 peles enviadas para ele. Os mercadores de Montevidéu divulgaram essa informação - não somente para seu parceiro em Salvador da Bahia encarregado de executar a dívida, mas também entre seus parceiros de negócios no Rio de Janeiro. Tal comportamento era característico de operaçóes de negócios nas sociedades do Antigo Regime: redes estruturadas garantiam a confiança e a segurança das operaçóes. ${ }^{42}$

Dentre os documentos confiscados, havia listas de bens pedidos por Cipriano de Melo - para sua família, para o governador de Montevidéu, e para o primer comandante del Resguardo, don Antonio Pereira - que incluía diversas peças de mobília de jacarandá, camisas, vestidos de veludo, partituras de saltério, um músico escravo e cozinheiros escravos. Todos esses itens e escravos eram para uso pessoal ou para as casas de suas famílias. Além disso, listas que especificavam itens à venda também foram encontradas. ${ }^{43}$

O vice-rei utilizou as provas encontradas dentre os pertences de Acuña para argumentar contra a primazia de Montevidéu como porto obrigatório da regiáo. Ele reforçou seu argumento ao enfatizar a corrupçáo das autoridades de Montevidéu, a quem ele acusou de proteger o contrabando com os portugueses. Além disso, o vice-rei advogou contra as políticas liberais de comércio neutro e viu a necessidade de "fechar as portas aos comerciantes portugueses", assim como aos britânicos, "mesmo que isso signifique permitir que seus navios afundassem em frente ao porto". O marquês de Loreto também indiciou diretamente a Cipriano de Melo, definido pelo vice-rei como um "oficial corrupto, receptivo a subornos", "um estrangeiro" e "um português, cuja conduta e desempenho eram danosos ao Tesouro Real" ${ }^{4}$

Em sua defesa, Cipriano de Melo apresentou uma lista de todos os serviços que havia realizado para a Coroa espanhola: participação em açôes militares durante a guerra em 1777, a conquista da Colônia do Sacramento e expediçôes para garantir o controle da Patagônia e das Malvinas (Ilhas Falkland). Além disso, ele forneceu uma lista de todo o contrabando confiscado por ele desde que assumiu o posto de segundo comandante del Resguardo. Cipriano de Melo também citou cânones de direito natural justificando as licenças para navios estrangeiros ancorarem em Montevidéu para reparos e revisou as ordenanças reais relacionadas ao comércio com navios de naçôes amigas. ${ }^{45}$

Em especial, Cipriano de Melo afirmou sua lealdade inquebrável à Coroa espanhola, como segue: "É fato público e bem conhecido que eu era residente (vezino) da Colônia do Sacramento; portanto, eu não devo ser considerado estrangeiro, e prefiro constar nos autos como espanhol, com todos os direitos e privilégios que gozam os súditos espanhóis". Cipriano de Melo argumentou que, de acordo com as leis de conquista, os residentes que desejassem jurar lealdade gozariam de direitos completos como vassalos da Coroa espanhola. ${ }^{46}$

\footnotetext{
${ }^{41}$ Ibidem. As operaçóes envolveram a compra de escravos, açúcar, tabaco, mobília, tecidos e roupas. Os valores mencionados em recibos individuais eram de 30 mil, 1.400, 13 mil e 7 mil pesos.

${ }^{42}$ Ibidem.

${ }^{43}$ Ibidem.

${ }^{44}$ Ibidem.

${ }^{45}$ Representacion de Manuel Cipriano de Melo. AGI, Gobierno, Buenos Aires. Leg 311.

${ }^{46}$ Ibidem.
} 
Cipriano de Melo também afirmou que a chegada dos comerciantes portugueses garantiu o fluxo contínuo de escravos durante os anos de guerra contra a Grá-Bretanha. Além disso, ele utilizou tal argumento para justificar seu envolvimento com Antonio Juan de Acuńa que, de acordo com Cipriano de Melo, era um dos agentes envolvidos no comércio de escravos. As reformas bourbônicas tinham a intenção de estimular a entrada de escravos nas Américas a fim de explorar a produção na agricultura. Entretanto, as políticas dirigidas para encorajar a aquisiçáo de escravos no império acabaram por reforçar a tradicional rota comercial entre o rio da Prata e o Rio de Janeiro. Após as guerras de 1777, o rei havia autorizado que certos súditos importassem seu capital da América portuguesa para a América espanhola. O intendente do rio da Prata, Francisco de Paula Sanz, afirmou que o comércio com os portugueses beneficiava o império, principalmente devido à entrada de escravos. O intendente Sanz também argumentou que tal fluxo de capital favorecia o império espanhol e, portanto, não deveria ser marcado como contrabando. ${ }^{47}$

O que iniciou como conflito local logo alcançou o Conselho das Índias, em Sevilha, como confronto entre o intendente (cuja jurisdição incluía a Comandancia del Resguardo) e o vice-rei (que tinha jurisdição sobre os oficiais alfandegários). Em suma, o conflito local transformou-se em imperial, entre a antiga estrutura de poder e os apoiadores das reformas recém-instituídas. Tal disputa é um exemplo claro de como elites locais e autoridades interpretavam e manipulavam a legislação colonial de acordo com os próprios interesses. Em 1788, Sanz foi enviado a Potosí como novo intendente do Alto Peru e o vice-rei foi substituído em Buenos Aires. Os oficiais de Montevidéu retiveram a jurisdição sobre todos os desembarques de transatlânticos no rio da Prata. Em detrimento do fato de que a atividade portuária de ambas as cidades complementavam-se, tal resultado náo significou o fim do conflito entre as facçôes das comunidades mercantis de Montevidéu e Buenos Aires.

Os inimigos de Cipriano de Melo apresentavam queixas ao Conselho das Índias, acusando-o e don Manuel Diago, seu parceiro de negócios, de contribuições fraudulentas que haviam levado a Casa da Alfândega de Buenos Aires à falência, e de contrabandear bens para o Brasil e La Habana. ${ }^{48}$ Em sua defesa, ele enfatizou a falta de provas conectando-o à corrupção na Casa da Alfândega de Buenos Aires, e por sua vez culpando a influência do vice-rei Loreto sobre o fiscal do Conselho das Índias. Cipriano de Melo denunciou o vice-rei pelas falsas acusaçóes contra ele, e ao fiscal por falhar no processamento dos documentos que ele havia enviado para o conselho. Além disso, Cipriano de Melo acusou a ambos de perseguição, "já que ele havia jurado vassalagem ao Rei da Espanha e, portanto, havia negado seu estado de súdito português". ${ }^{9}$

Com relação às acusações de contrabando, Cipriano de Melo apresentou uma defesa de que todo o comércio com La Habana havia sido conduzido por sua esposa, Ana Joaquina da Silva e, portanto, não tinha relação alguma com ele. Após um processo longo e arrastado, ficou decidido que sua esposa havia obtido permissão dele para comercializar e Cipriano de Melo foi julgado culpado de contrabandear escravos e outros bens. Como resultado, Cipriano de Melo ficou preso por um curto período de tempo em Buenos Aires, em 1788. Entretanto, o rei reafirmou o estado de Cipriano de Melo como espanhol naturalizado e permitiu que ele retomasse seu posto, com a proibição de comercializar escravos e

\footnotetext{
${ }^{47}$ Parecer sobre pedido de Francisco Mendes Ribeyro para pasar al Rio de Geneiro. Buenos Aires, 24 mayo 1785. AGI, Buenos Aires Gobierno, leg. 333. Além do caso de Cipriano de Melo, Sanz mencionou o caso Francisco Mendez Ribeyro, outro português que vivia em Buenos Aires ao qual se lhe foi negado o pedido para a importaçáo da herança recebida de um irmão falecido em terras fluminenses.

${ }^{48}$ Archivo General de la Nación, Argentina (AGN, Argentina), Sala IX, 33-4-5, Hacienda, exp. 41; e AGN, Argentina, Sala IX, 31-16-6, Justicia, 1791. As denúncias de contrabando envolviam também sua esposa Ana Joaquina Silva. As acusaçóes envolviam o contrabando de charque, cera, sebo, velas e escravos.

${ }^{49}$ Rl. Orden que Remitan los Documentos relativos a la defensa de Dn. Man. Cipriano de Melo 2o. Comandte. De los Resguardos y de Dn. Manuel Diago. AGN, Argentina, Sala IX, 31-16-6, Justicia, 1791.
} 
outros bens. O banimento não impediu que sua esposa conduzisse uma série de transaçôes comerciais envolvendo escravos, açúcar e tabaco, bem como uma série de acordos transimperiais com a América portuguesa, a Europa, Potosí, Chile e La Habana..$^{50}$ Além disso, don Manuel Diago recuperou seu direito de atuar em atividades de comércio. Consequentemente, a parceria comercial entre Diago e Cipriano de Melo durou até a morte deste, em 1813.

Mesmo após os incidentes de 1788, don Cipriano de Melo continuou sendo membro ativo da elite de Montevidéu. Ele fundou o primeiro teatro na cidade, conhecido como Casa de Comédias, e serviu como gerente do Hospital de Caridade, instituição de posse e instrumentalização da Irmandade de São Francisco. Durante a década de 1790, ele teve envolvimento com a comunidade luso-brasileira residente em Montevidéu, patrocinando e dando assistência a imigrantes recém-chegados do Brasil, dando atenção especial a artesãos. Ele também manteve redes ativas com autoridades portuguesas, garantindo inclusive a passagem de navios portugueses em Montevidéu que transportassem missionários franciscanos. ${ }^{51}$ Tais fatos demonstram a integração bem-sucedida de Cipriano de Melo na vida social e institucional da cidade, com destaque para a natureza transimperial da sociedade local e de instituiçóes comunitárias.

A década de 1790 marcou o início de uma etapa na qual Cipriano de Melo não tinha mais a permissão de se envolver diretamente no comércio do Atlântico. Entretanto, ele continuou a reprimir o contrabando no porto de Montevidéu, na lagoa Merin, e na regiáo de fronteira entre as Américas portuguesa e espanhola. Em Montevidéu, Cipriano de Melo inspecionou pessoalmente muitos dos navios que chegavam de colônias estrangeiras. ${ }^{52}$ Tais navios frequentemente carregavam antigos conhecidos ou parceiros de negócios e seus agentes como passageiros. Na região de fronteira com o Brasil, Cipriano de Melo conduziu diversas batidas, estabeleceu postos de guarda e enviou canoas para reprimir o contrabando nas águas da lagoa. ${ }^{53} \mathrm{Em}$ tais operaçóes anticontrabando, Cipriano de Melo contava com o auxílio de Rafael Pinto Bandeira, mercador e oficial português. Bandeira havia sido acusado de monopolizar o contrabando na região, mas tais denúncias nunca chegaram a condenaçóes. ${ }^{54}$

A última década do século XVIII viu a guerra entre a Espanha e outros impérios atlânticos. Os conflitos recorrentes encorajaram oficiais espanhóis a aprovar leis que autorizassem o comércio com navios de naçôes amigas. Entre os anos de 1795 e 1797, o porto de Montevidéu ficou oficialmente aberto para navios vindos de Portugal e outras naçóes amigas. Como ocorrido na década anterior, os mercadores de Montevidéu no rio da Prata, bem como algumas facçôes de Buenos Aires, viram anos de vasta oportunidade para o comércio transimperial. Entretanto, a década de 1790 marcou mais uma disputa entre grupos centralizados em Buenos Aires e em Montevidéu. Desta vez, os interesses comerciais colocaram antigos aliados em oposição: as autoridades e mercadores de Montevidéu contra o grupo de mercadores de Buenos Aires associados envolvidos no comércio com estrangeiros. ${ }^{55}$

Durante anos, em meados da década de 1790, sinais óbvios da quebra de aliança (entre comerciantes de Montevidéu e mercadores de Buenos Aires) e a disputa pela primazia do comércio transimperial

\footnotetext{
${ }^{50}$ Inventário de Ana Joaquina da Silva, 1821, Archivo Judicial, Uruguay, caja 203, Civil 1. Agradeço a Alex Borucki por proporcionar acesso a este documento.

${ }^{51}$ Declaração assinada pelo Marques de Aviles. AGI, Indiferente General Leg. 2466. 1799.

52 Auto de Embarcacion. Montevideo, 20 feb. 1797. AGN, Uruguay, Escribanía de Gobierno y Hacienda, caja 34; Auto de Embarcacion. Montevideo, 18 feb. 1797. AGN, Uruguay, Escribanía de Gobierno y Hacienda, caja 34; Auto de Embarcacion. Montevideo, 14 dic. 1799. AGN, Uruguay, Escribanía de Gobierno y Hacienda, caja 40; Auto de Embarcacion. Montevideo 23 nov. 1799. AGN, Uruguay, Escribanía de Gobierno y Hacienda, caja 40; Auto de Embarcacion. Montevideo 19 dic. 1799. AGN, Uruguay, Escribanía de Gobierno y Hacienda, caja 40; e Auto de Embarcacion. Montevideo, 13 mar. 1793. AGN, Uruguay, Escribanía de Gobierno y Hacienda, caja 18.

53 Auto de Embarcacion. AGN, Uruguay, Escribanía de Gobierno y Hacienda, caja 18, 9 V, 1792.

${ }^{4}$ GIL, Tiago Luís. Infiéis transgressores: os contrabandistas da fronteira (1760-1810). Dissertação (mestrado) Universidade Federal do Rio de Janeiro, Rio de Janeiro, 2002.

${ }^{55}$ Juez de Arribadas. AGN, Uruguay. EGH Caja 25. Exp. 89. 1794.
} 
apareceram pela primeira vez. Como chefe da agência encarregada de reprimir o contrabando, Cipriano de Melo realizou uma série de confiscos que tinha como alvo navios e tripulaçóes de mercadores porteños envolvidos no comércio transimperial. Os processos, combinados com o contrabando confiscado na década de 1790, serviram de testemunho para a divisão entre a facção de Montevidéu, composta por don Francisco Manuel, Cipriano de Melo e Melchor de Viana, e a facção de Buenos Aires, composta por Tomás Antonio Romero, Pedro Duval e José de Maria, entre outros. ${ }^{56}$

O monopólio dos desembarques transatlânticos nos portos de Montevidéu era a base do conflito entre as facções mercantis envolvidas com o comércio com portugueses e anglo-americanos. Na década de 1790, a comunidade mercantil de Buenos Aires já estava claramente dividida internamente: entre os mercadores contrários ao comércio com navios de potências amigas e aqueles a favor de tais práticas. ${ }^{57}$ Como resultado, facções mercantis de Buenos Aires iniciaram, com apoio do Consulado de Comércio, um processo nos quais os mercadores argumentavam contra a posição de Montevidéu como cidade portuária privilegiada no rio da Prata. ${ }^{58}$ Entretanto, dessa vez os alvos de maior visibilidade entre as autoridades de Montevidéu eram Cipriano de Melo e o novo vice-rei do rio da Prata e antigo governador de Montevidéu, don Olaguer Feliú.

O principal incidente que solidificou a cisma entre os mercadores de Buenos Aires e Montevidéu, outrora aliados, envolveu a primazia de Montevidéu como porto obrigatório na regiáo. O grupo porteño depreciou os excessos do vice-rei e do comandante del Resguardo Cipriano de Melo que, de acordo com seus argumentos, "ameaçavam a primazia da capital Buenos Aires" e impunham "perdas miseráveis" ao comércio livre. ${ }^{59} \mathrm{O}$ grupo de homens de negócios de Buenos Aires, representados por Juan de Aguírre, José de Maria e Pedro Duval, reclamava da imposição da política estipulando que o primeiro desembarque de todos os navios vindos de colônias estrangeiras fosse realizado no porto de Montevidéu.

O episódio pivô deste conflito foi quando dois navios, vindos das Ilhas Maurício e de Pernambuco, não obtiveram permissão de entrada no porto de Buenos Aires. Tais navios eram da posse de don Pedro Duval e don Juan de Aguirre, dois poderosos mercadores de Buenos Aires e membros do Consulado de Comércio. Os mercadores reclamaram que seus navios, carregados com bens perecíveis e escravos, tiveram seu desembarque em Buenos Aires negado devido ao decreto do vice-rei Olaguer Feliú requerendo que todo o comércio transatlântico fosse conduzido pelo porto de Montevidéu. Além disso, os mercadores peticionaram que o vice-rei designasse um oficial para inspecionar os navios sem ter de voltar para Montevidéu. O vice-rei Olaguer Feliú designou o comandante del Resguardo de Montevidéu, Cipriano de Melo, para realizar a tarefa. Entretanto, Cipriano de Melo não se encontrava em Buenos Aires e, consequentemente, os navios foram forçados a partir de lá. ${ }^{60}$

Em uma tentativa de contornar o retorno a Montevidéu, Duval e Aguirre levaram seus navios até a Colônia do Sacramento, porto sob jurisdição dos porteños, e mais tarde de volta ao porto de Buenos Aires sob o disfarce de navios recém-chegados de outro porto espanhol. Entretanto, tal manobra não produziu o resultado esperado e os navios eventualmente partiram para Montevidéu. Os mercadores reclamaram que tais regras não somente impediam o desembarque de sua carga, mas também causaram

\footnotetext{
${ }^{56}$ Dna. Maria del Carmen vs. Dn. Miguel de Fleytas. Montevideo, 19 set. 1794. AGN, Uruguay, Escribanía de Gobierno y Hacienda, caja 22. Neste caso, Cipriano de Melo testemunhou contra Miguel de Fleytas, que trabalhou para Tomás Antonio Romero. Decomiso de Pedro Duval, Casimiro Necochea, Miguel Josef Fleytas, et alii, Montevideo, 22 feb. 1800. AGN, Uruguay, Escribanía de Gobierno y Hacienda, caja 46.

${ }^{57}$ GRIECO, Viviana L. Politics and public credit, op. cit.

58 Declaração firmada por Josef de Maria. Buenos Aires, 1798. AGI, Buenos Aires Gobierno, Leg. 346. O mercador defende o comécio com navios neutros, mas argumenta contra a primazia de Montevidéu.

${ }^{59}$ Representacion del Real Consulado contra el Comercio de Frutos de esta Provincia con las Colonias Estranjeras, AGI, Buenos Aires Gobierno, Leg. 346. 1797.

${ }^{60}$ Ibidem.
} 
danos materiais e perda de escravos em grande número ao passarem por uma tempestade a caminho de Montevidéu. ${ }^{61}$ Os mercadores também argumentaram que Buenos Aires deveria ter permissão de receber navios com escravos - não somente porque a cidade fornecia o capital necessário para financiar tais expedições, mas também porque o porto tinha melhor logística para o desembarque de escravos.

Os mercadores Pedro Duval e José de Maria chamaram os oficiais da Comandância del Resguardo de "burocratas ruins e infiéis", declarando que as autoridades de Montevidéu e o próprio vice-rei tencionavam manter monopólio sobre o comércio transimperial e o contrabando. ${ }^{62} \mathrm{~A}$ acusaçáo deixou implícita uma sugestão dos mercadores de que o comércio ilícito não ocorria em Buenos Aires. Além disso, os mercadores portenhos e seus aliados argumentavam que a extensão da autoridade de um oficial de Montevidéu até Buenos Aires, no caso Cipriano de Melo, constituía séria ofensa aos burocratas da capital do vice-reinado. Em suas estimativas, a mudança "representaria a influência de Montevidéu sobre Buenos Aires". Eles também alegavam que o vice-rei Olaguer Feliú passava mais tempo em Montevidéu, onde mantinha seu lar, do que em Buenos Aires. ${ }^{63}$

Além disso, José de Maria também alegava que o vice-rei Olaguer Feliú havia falhado em honrar as licenças para o comércio transimperial garantidas pelo vice-rei anterior, e que tais medidas faziam dos mercadores de Buenos Aires um alvo injusto. ${ }^{64}$ Maria também afirmou que o vice-rei Olaguer Feliú era fortemente associado com certo "Melo", a quem ele dava mais autoridade do que era legalmente permitido. ${ }^{65}$ José de Maria e Pedro Duval afirmaram que não queriam "mencionar os detalhes da presença de Feliú em Montevidéu, para evitar a reprodução de rumores e demonstrar falta de 'decoro", e para evitar a provocação de maiores inquietaçôes nas ruas de Buenos Aires. ${ }^{66}$ Tais declaraçóes deixavam clara a cisma entre as comunidades das duas cidades portuárias; embora o conflito tenha começado como um problema político e econômico, os mercadores puderam utilizar suas redes verticais e horizontais para mobilizar as pessoas fora dos confins da comunidade mercantil. ${ }^{67}$

A disputa culminou na tentativa da comunidade mercantil de Montevidéu de criar seu próprio Consulado de Comércio, enquanto os mercadores de Buenos Aires fizeram esforços para autorizar o porto da Ensenada de Barragán, uma baía ao sul de Buenos Aires, como porto transatlântico. A iniciativa dos mercadores de Buenos Aires foi bem-sucedida por algum tempo. De 1801 a 1802, o porto da Ensenada de Barragán foi declarado como extensão física do porto de Buenos Aires e foi aberto para navios espanhóis navegando em rotas transatlânticas. Entretanto, navios estrangeiros não tinham permissão de entrar. Apesar da rejeição do Conselho das Índias pela criação de um novo Consulado de Comércio em Montevidéu, os argumentos a favor do retorno da primazia ao porto de Montevidéu foram bem recebidos. ${ }^{68}$ Após 1802, Montevidéu retomou seu papel como porto principal para viagens transatlânticas no estuário do rio da Prata. Assim, no início do século XIX, um novo equi-

\footnotetext{
${ }^{61}$ Ibidem.

62 "malos y infieles servidores”. Declaração assinada por Pedro Duval, Buenos Aires, 30 abr. 1798. AGI, Buenos Aires Gobierno, Leg. 346. AGI, Buenos Aires Gobierno, Leg. 346.

${ }^{63}$ Representacion del Real Consulado contra el Comercio de Frutos de esta Provincia con las Colonia Estranjeras, AGI, Buenos Aires Gobierno, Leg. 346. Statement signed by Pedro Duval, Buenos Aires, 30 abr. 1798. AGI, Buenos Aires Gobierno, Leg. 346.

${ }^{64}$ Ibidem.

${ }^{65}$ Ibidem.

${ }^{66}$ Ibidem.

${ }^{67}$ Hugo Raúl Galmarini também observa o conflito entre grupos mercantis em Buenos Aires. Distintos grupos, mais ou menos associados com o comércio transimperial e tráfico, e comerciantes previamente vinculados ao comércio peninsular conflitam no Consulado de Comércio, mas com reflexos até mesmo nas ruas de Buenos Aires. Tais conflitos ganhavam importância também nas ruas, tamanho o papel das facçóes em Buenos Aires no período. GALMARINI, Hugo Raúl. Los negocios del poder: reforma y crisis del estado, 1776-1826. Buenos Aires: Corregidor, 2000. p. 53.

${ }^{68}$ Representacion del Real Consulado contra el Comercio de Frutos de esta Provincia con las Colonia Estranjeras, AGI, Buenos Aires Gobierno, Leg. 346.
} 
líbrio de poderes havia sido estabelecido no rio da Prata. Apesar de continuar a realizar negócios em conjunto, as comunidades de mercadores em Buenos Aires e Montevidéu tinham interesses claramente diferentes.

Cipriano de Melo havia protagonizado muitos dos conflitos gerados pela transformação de Montevidéu no centro do poder regional. Entretanto, na primeira década do século XIX as açôes de Cipriano de Melo não tiveram os mesmos resultados das décadas anteriores. Ainda assim, ele manteve suas redes e influência na região. Em 1809, o governador do Rio Grande do Sul, capitania do extremo sul do Brasil, enviou a Cipriano de Melo caixas de doces como resposta a jornais portugueses que ele havia recebido anteriormente. O governador agradeceu a Cipriano de Melo, dizendo que não havia tido a oportunidade de abrir uma gazeta portuguesa há meses. Apesar de pequeno, este episódio ainda demonstra como Cipriano de Melo continuou a nutrir suas importantes ligações transimperiais. ${ }^{69}$

Quando a crise de legitimidade política que levou aos movimentos de independência teve início, Cipriano de Melo apoiou a Junta de Montevidéu e, subsequentemente, a invasão portuguesa da cidade. Entretanto, Cipriano de Melo faleceu em 1813, no conforto de seu lar, enquanto Montevidéu estava sob cerco militar pelas tropas enviadas de Buenos Aires..$^{70}$ No momento de sua morte, ainda havia mais de 37 mil pesos a serem cobrados de seus parceiros de negócios em Montevidéu e no Rio de Janeiro. Do total, 36 mil pesos eram de atividades comerciais e mil pesos eram relacionados a um empréstimo dado a um artesão português que Cipriano de Melo havia ajudado a estabelecer residência em Montevidéu. O capital total acumulado por Cipriano de Melo em sua vida ultrapassou a soma de 186 mil pesos.

\section{Conclusão}

A história de vida de don Cipriano de Melo e suas ligaçóes que ultrapassaram os limites imperiais - passando pelo Alto Peru, Rio de Janeiro, África e Europa - expóem a fluidez das fronteiras políticas ao fim do século XVIII. Além disso, o caso de Cipriano de Melo ilumina a significância das redes transimperiais para as regiốes periféricas, demonstrando como a manipulação de recursos transimperiais em conjunto com a legislaçáo imperial permitiu que grupos locais melhorassem seu status dentro do sistema imperial. Tal status melhorado era, por sua vez, utilizado para obter autonomia em relação aos centros regionais de poder.

Os conflitos políticos e econômicos, dos quais don Cipriano de Melo participou, eram em grande parte disputas entre interesses políticos e comerciais conflitantes da capital do vice-reinado (Buenos $\mathrm{Ai}$ res) e da capital da província em ascensão (Montevidéu). De fato, as reformas bourbonônicas e as redes transimperiais conectadas aos portugueses e anglo-americanos constituíram as raízes da emergência de Montevidéu como centro regional. A sociedade de Montevidéu desenvolveu maior noção de sua própria economia e política dentro do império espanhol ao manipular o discurso imperial e a nova legislação em seu favor, beneficiando-se ainda mais do capital social e econômico que havia sido transferido da Colônia do Sacramento.

A história de vida de Cipriano de Melo, cuja experiência foi também a de muitos de seus contemporâneos, traz mais um nível de entendimento acerca das mudanças ocorridas no Atlântico ao fim do período colonial. As redes sociais que transcendiam os limites políticos dos impérios atlânticos eram cruciais para a formação de processos econômicos, políticos e sociais que se desdobraram dentro de

\footnotetext{
${ }^{69}$ Diogo de Souza a Manuel Cipriano de Melo. Porto Alegre, 1810. Arquivo Histórico do Rio Grande do Sul, A1.06. Diogo de Souza a Manuel Cipriano de Melo. Porto Alegre, 1810. Arquivo Histórico do Rio Grande do Sul, A1.02.

${ }^{70}$ BENTANCUR, Arturo Ariel. Don Cipriano de Melo, señor de fronteras, op. cit. p. 126-127. A casa de Cipriano de Melo fica na Cidade Velha de Montevidéu e atualmente serve como o Museo Casa de Lavalleja.
} 
espaços imperiais. A carreira de Cipriano de Melo revela a importância das redes que ligavam agentes históricos além dos limites políticos de impérios, em um Atlântico interligado. Além disso, em áreas periféricas, agentes históricos puderam encontrar em tais ligaçôes transimperiais mais oportunidades alternativas para acumular lucros políticos e econômicos do que aquelas oferecidas pelos centros de poder imperial.

\section{Figura 1}

\section{Redes de don Manuel Cipriano de Melo}

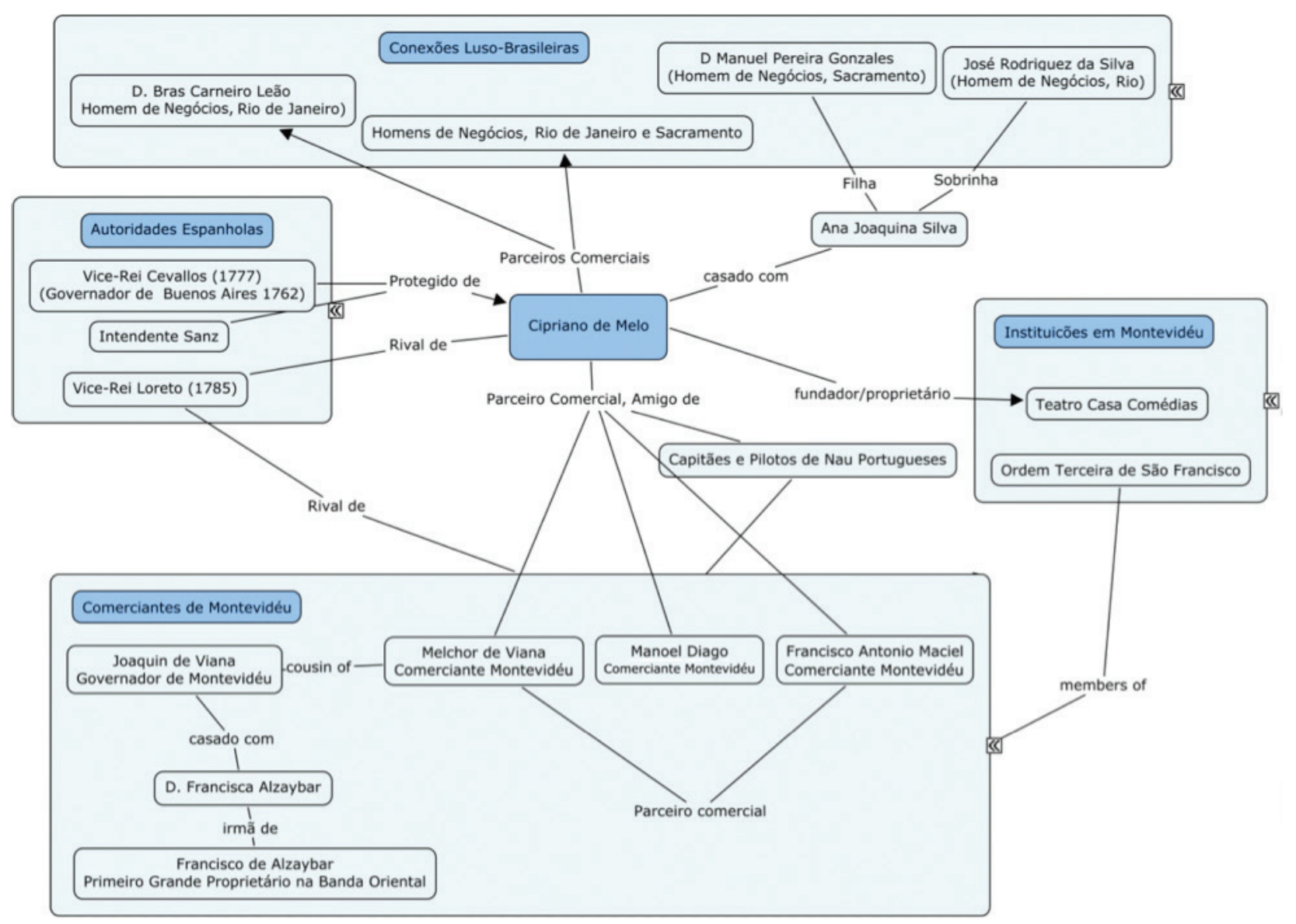

